\title{
The accuracy of ultrasound in the estimation of the actual birth weight at term pregnancies in a sample from Erbil city
}

\begin{abstract}
Background and objectives: Estimation of fetal weight is an important component of maternity health care, especially in the management and planning of the delivery mode, and this will play a big role in newborn and maternal safety. This study has been carried out for providing more knowledge about the accuracy of fetal weight estimation by ultrasound and its correlation with actual weight after birth.

Methods: This study was performed in the Radiology Department of the Maternity Teaching Hospital in Erbil city on 407 pregnant women with singleton and in term pregnancies from May $4^{\text {th }}, 2015$ to April $10^{\text {th }}, 2016$. The ultrasound examination typically involved estimating fetal weight by using both Hadlock's and Shepard's formula, and the actual birth weight of each participant's neonate was measured immediately after delivery by using a standardized neonatal weighing scale. This study was approved by the Research Ethics Committee of Hawler Medical University.

Results: Statistical analysis by t-test indicated that there was a significant difference between the actual birth weight and sonographic estimation of fetal weight using both formulas. The correlation between actual birth weight and sonographic estimation by Hadlock's formula was $(R=0.869)$ while it slightly declined when Shepard's formula was used $(R=0.805)$. Hadlock's formula showed a better relation with actual fetal weight. This study was showed higher correlation when the time of estimation was within seven days of delivery time, and it was about $(R=0.921)$, and when the time of estimation became more than seven days from delivery, it was showed less correlation $(R=0.811)$.

Conclusion: Hadlock's formula for estimation of fetal weight by ultrasound showed more accurate results, particularly within a time less than seven days from delivery date.
\end{abstract}

Keywords: Sonography; Pregnancy; Fetal parameters; Fetal weight.

\section{Introduction}

Estimation of fetal weight has an important role in maternity care especially in counseling, differential diagnosis, and management of labor and delivery mode, ${ }^{1-3}$ and it has a great influence on fetal and neonatal morbidity, ${ }^{4-6}$ especially in the low birth weight, and macrosomic newborn. Since counseling on survival rate, route of delivery, and level of hospital care needed for each case based mainly or in part on the sonographic estimation of the birth weight. $^{7,8} \mathrm{~A}$ variety of methods has been proposed for estimation of fetal weight, and the two main methods are clinical and ultrasonography. 1,2,7,8 Many studies indicated that ultrasonographic estimation of fetal weight gives a better result for prediction of fetal weight than other methods. ${ }^{1,2}$ A variety of formulas and parameters have been correlated with sonographic estimation of fetal weight, ${ }^{1,9,10,11}$ ultrasound examination involves measurement of different biometric parameters that are involved in a formula for calculating fetal weight. Most commonly, a combination of biparietal diameter, head circumference, abdominal circumference, femur length and other parameters are used in different formulas

* Ministry of Health, Erbil, I raq.

** Department of Radiology, College of Medicine, Hawler Medical University, Erbil, I raq. 
for fetal weight estimation. Shepard's and Hadlock's formulas are commonly used for fetal weight estimation; these formulas are included in most ultrasound equipment's. ${ }^{9-12}$ Estimation of fetal weight from the Shepard and the Hadlock's formulas appear to have some variation from actual neonate weight as shown in many studies. ${ }^{2,10,12-14}$ In a study by Hadlock'set al found that combining of three parameters formula produced a more accurate result than the use of only two parameters formula. ${ }^{9}$ Conversely, other studies found no improvement in predictive accuracy over that of formulas using two parameters. ${ }^{13,14}$ There are many formulas and methods for fetal weight estimation by ultrasound, and there were still a percentage of errors in these formulas as shown in many studies ${ }^{1,10-12}$ which may affect the planning and management of delivery mode and maternal health. Therefore, this study was designed to determine the most accurate formula between Shepard's and Hadlock's for the estimation of fetal weight and its correlation with actual weight after birth in these methods in -term pregnancies.

\section{Methods}

This study was a prospective study conducted in the Radiology Department of Maternity Teaching Hospital in Erbil city on 407 pregnant women, from May $4^{\text {th }}$, 2015 till April $10^{\text {th }}, 2016$. The examination had been performed by a single radiologist, using PHILIPS ultrasound machine, 2-5 $\mathrm{MHz}$ convex transducer. Ultrasound examination typically involved measurement of different biometric structures that are incorporated into a formula for calculating estimated fetal weight (EFW). Most commonly, a combination of biparietal diameter (BPD), abdominal circumference (AC) were used in Shepard's formula and a combination of biparietal diameter (BPD), abdominal circumference $(A C)$, and femoral length $(F L)$ were used in Hadlock's formula, ${ }^{1,9,10}$ and all the data for fetal weight estimation by both formulas were tabulated to be analyzed statistically. A term pregnancy is defined as the period of gestation from 37 completed weeks up to 41 completed weeks and six days. ${ }^{15}$ All estimates were based on the sonographic determination (0-7 days) before suspected delivery time $^{10,12}$ and the time was extended in this study according to real delivery time and patient visit time for new sonographic examination. After delivery, the weight of each participant's neonate was measured within 30 minutes by trained assistants (nurses) using a standardized neonatal weighing scale. The estimated fetal weight was adjusted by adding $25 \mathrm{~g}$ for each day between the ultrasound fetal weight estimation and delivery date. ${ }^{10}$ The sampling method is a nonprobability; convenient sampling involving 407 women with an uncomplicated singleton at term pregnancies (completed 37 weeks) with cephalic presentation and intact membranes. Their gestational age determination was calculated depending on their precise last menstrual period (LMP) and further confirmed by their early pregnancy ultrasound before 20 weeks. The pregnant lady was asked to empty her bladder, then lie down in the supine position. Pregnant women with obesity $\left(\mathrm{BMI} 30 \mathrm{~kg} / \mathrm{m}^{2}\right.$ ) or greater, ${ }^{16,17}$ premature rupture of membranes, antepartum hemorrhage, and congenital fetal anomalies were excluded as well as ladies with preeclampsia, oligohydramnios or polyhydramnios and uterine fibroids. ${ }^{2,6}$ The data were recorded and saved onto a computer and analyzed with the statistical package for the social sciences computer software (version 19.0). Paired Student's t-test was used for comparing the accuracy of sonographic fetal weight versus the actual birth weight. A $P$ value $<0.05$ was regarded as significant and correlation coefficient were used to assess the relation between the two variables estimated and actual fetal weight. 


\section{Results}

This study was performed on 407 adult pregnant ladies, their ages range were between 18 to 41 years, and their mean age was $28.5 \pm 4.1$ years. The gestational age of the newborn baby was between 37.2 and 41.4 weeks at the time of delivery. From Table 1 the following results can be concluded that the mean of the actual birth weight was (3231g) and their weight at birth was between (2000-4500g), their estimated weight by ultrasound Hadlock's formula was between (2119-4175g) Their mean was $3268 \mathrm{~g}$, while the estimated weight by ultrasound Shepard's formula was between $2156 \mathrm{~g}$ and $4180 \mathrm{~g}$ and their mean was $3296 \mathrm{~g}$. The results from the Table 2 indicated that there were significant differences between the actual birth weights and the sonographic estimation in both formulas of the study,

Table1: The analysis of the main data in this study.

$\begin{array}{llll}\text { Mean Minimum-Maximum Range SD } & \text { C.V \% }\end{array}$

\begin{tabular}{lccccc} 
Gestational age (week) & 39.1 & $41.4-37.2$ & 4.2 & 1.018 & $2.6 \%$ \\
$\begin{array}{l}\text { Actual birth weight (g) } \\
\begin{array}{l}\text { Estimated fetal birth } \\
\text { weight (g) by Hadlock's } \\
\text { formula }\end{array}\end{array} \quad 3231$ & $2000-4500$ & 2500 & 479.080 & $14.8 \%$ \\
$\begin{array}{l}\text { Estimated fetal birth } \\
\text { weight (g) by Shepard's } \\
\text { formula }\end{array}$ & 3296 & $2119-4175$ & 2056 & 422.361 & $13 \%$ \\
\hline
\end{tabular}

Table 2: Statistical analysis by t-test for comparing fetal weight estimation in both Hadlock's and Shepard's formulas with actual birth weight.

Mean SD Std. Error Correlation t-value $P$ value

Actual birth weight with / Estimated fetal weight by Hadlock's

Actual birth weight with / Estimated fetal weight by Shepard's

Estimated fetal weight by Hadlock's / Estimated fetal weight by Shepard's
3231

3268

237.469

11.771

0.869

3.071

0.002

3231

3296

288.871

14.319

0.805

4.478

0.001

3268

3296 
and it showed high correlation $(r=0.869)$ between actual birth weight and sonographic estimation by Hadlock's formula (Figure 1) while the correlation declined in Shepard's formula $(r=0.805)$ with actual birth weight as shown in Table 2 and Figure 2. This result indicated that weight estimation by Hadlock's formula showed a better correlation with actual fetal weight, and the correlation between the two formulas was about $93.1 \%$.

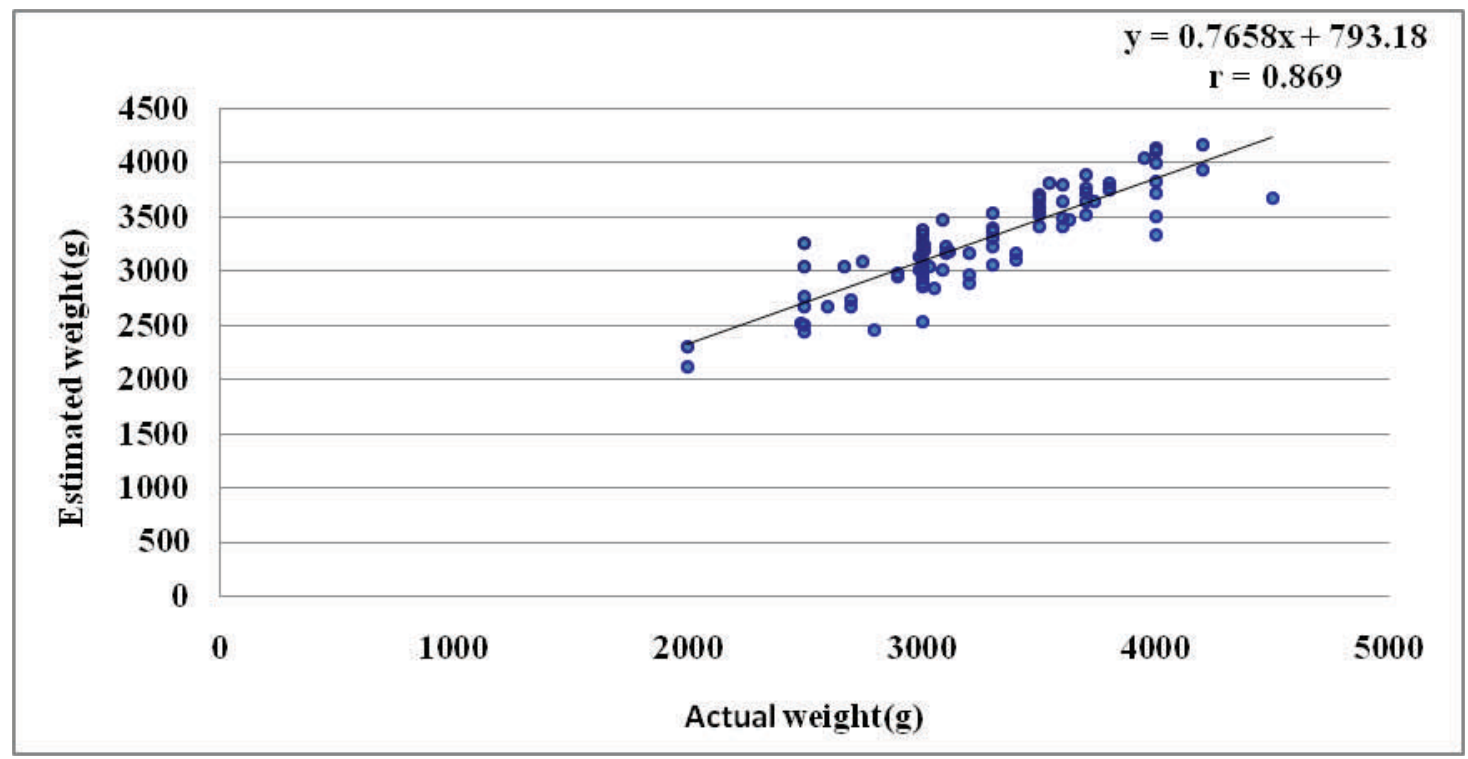

Figure 1: The correlation between actual birth weight and estimated weight by Hadlock's formula.

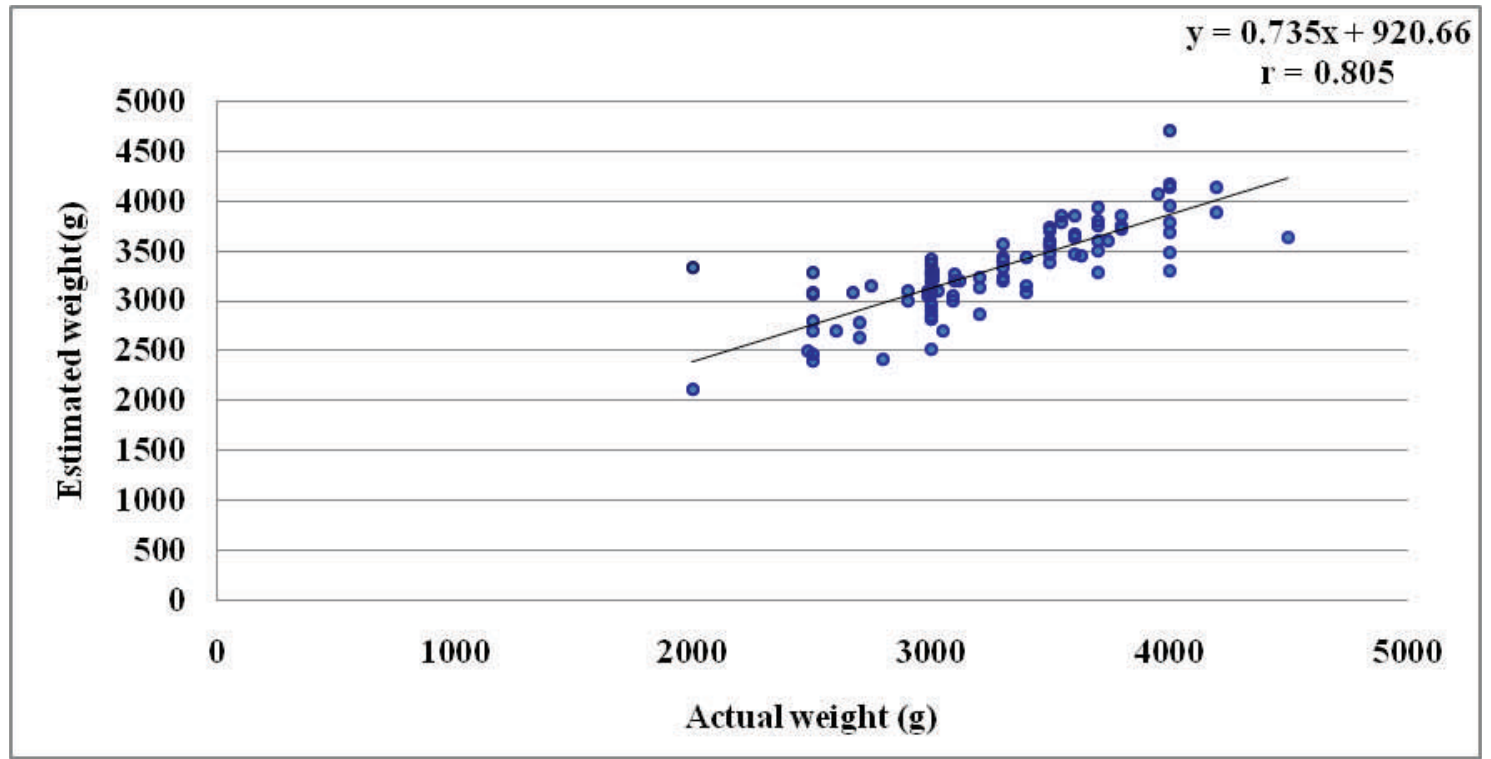

Figure 2: The correlation between actual birth weight and estimated weight by Shepard's formula. 
The results in Table 3 indicates that there was a significant difference between the estimated weight and actual weight in both periods of time, and the correlation was higher $(r=0.921)$ when the time of estimation was less than seven days from the delivery time, and it was decreased to $(r=0.811)$ when the time of estimation become more than seven days. The results from Table 4 showed that there was a significant difference in actual birth weights between genders and the mean weight of male newborn babies was $3303 \mathrm{~g}$ which was greater than female in this study while in female was $3160 \mathrm{~g}$.

\section{Discussion}

Accurate estimation of fetal weight by sonography is considered as one of the most significant findings, which provide a significant role in growth assessment and help for determination of the mode of delivery which has a great effect on maternal and neonatal safety. ${ }^{1,2,12}$ The mean of actual birth in this study was 3.231 $\mathrm{kg}$ which was nearly similar to the mean showed by many studies ${ }^{2,11,12}$, and it was in agreement with normal range of birth weight of child standard by World Health Organization $(\mathrm{WHO})^{18,19}$, and this reflects conventional condition of maternal health, environment, and diet, and it was slightly less than mean of birth weight $(2.482 \pm 354.1 \mathrm{~kg})$ of a study done in Erbil by Shahla at 2010 and some of other studi$\mathrm{es}^{1,9,20}$ and this variation may be due to several factors which affect the birth weight such as demographic changes due to popular migration from other cities as a result of crisis in this region, socioeconomic changes at the period of study, also variation in sample size and regional change with other studies with environmental factors may play a role in this variation in birth weight. The estimated birth weight mean by Hadlock's formula

Table 3: The statistical analysis by t-test for actual birth weight and sonographic estimated of fetal weight by Hadlock's formula when the time of delivery less than one week or more than one week from sonographic estimation time.

\begin{tabular}{|c|c|c|c|c|c|c|}
\hline & Mean (kg) & Correlation & St. Error & SD & $\mathrm{t}$ - value & $P$ value \\
\hline $\begin{array}{l}\text { Actual birth weight fewer } \\
\text { 7days }\end{array}$ & 3231 & & 31.56 & 454.17 & & \\
\hline $\begin{array}{l}\text { Estimated fetal weight by } \\
\text { sonography less than } \\
\text { seven days from delivery }\end{array}$ & 3187 & 0.921 & 31.39 & 451.66 & 3.59 & 0.004 \\
\hline $\begin{array}{l}\text { Actual birth weight more } \\
\text { than seven days }\end{array}$ & 3312 & & 27.27 & 382.2 & & \\
\hline $\begin{array}{l}\text { Estimated fetal weight } \\
\text { more than seven days } \\
\text { from delivery }\end{array}$ & 3109 & 0.811 & 35.51 & 498.53 & 3.89 & 0.027 \\
\hline
\end{tabular}

Table 4: Statistical analysis by ANOVA test for actual birth weight in male and female.

\begin{tabular}{lccccc}
\hline & Mean & SD & SE & F- value & $\boldsymbol{P}$ value \\
\hline $\begin{array}{l}\text { Actual birth weight for } \\
\text { male }\end{array}$ & 3305 & 484.02 & 34.14 & & \\
$\begin{array}{l}\text { Actual birth weight for } \\
\text { female }\end{array}$ & 3160 & 464.25 & 32.34 & 9.53 & 0.002 \\
\hline
\end{tabular}


was $3.268 \pm 422$, and by Shepard's formula was $3.296 \pm 437$ and when compared statistically with the actual birth weight it was found that there was a significant difference and this result agrees with many studies, ${ }^{1,9,10,12-14}$ which may be due to the following factors, the amount of differences which still present between actual birth weight and estimated weight by both formulas, $P$ value of t-test is function of both the sample size and the difference between the two groups, so it significance may be attributed to the sample size in this study, and the percentage of errors that may have occurred when three-dimensional structures measured by a radiologist for determining these parameters AC, BPD and $\mathrm{FL}$ from two-dimensional images of ultrasound. In contrast to the study done in Nigeria by Charles et al. 2014 which showed no significant differences between the actual birth weight and the estimated fetal weight, ${ }^{21}$ this study showed the reversed, this may be due to the variation in the sample size and the time of sonographic estimation, in that study was within 72 hours from the date of their delivery. Furthermore considering the significant correlation between Hadlock's formula and actual birth weight in this study $(R=0.869$, $P<0.05)$ which support and agree with results of these studies ${ }^{1,2,13}$ as they showed a high correlation between estimated weight and actual weight, while the estimation of fetal weight by Shepard's formula yield lower correlation ( $R=0.805$, $P<0.05)$ with actual birth weight and this result indicated that Hadlock's formula is more reliable in sonographic estimation of fetal weight, and this finding may be due to more measurement errors when we depend on fewer structures assessment, as there was anatomic and growth rate variation for different body structures which may affect the weight assessment by both formulas. This study concluded better sonographic assessment of weight when the assessment had been done in a time less than seven days as it was showed higher correlation $(R=0.921)$ and the correlation decline when this assessment was done in more than seven days $(R=0.811)$, and this is may be due to variation in growth rate of body structure which may be affected by many factors such as maternal diet, environmental factors, genetic causes and the way of assessment of birth weight by ultrasonic device according to these formulas, and this result agree with most study which advocated sonographic assessment of weight in time less than week from delivery time. 1,2,10,11,13,20-22 This study found that the newborn male gender have greater weight than female newborn, and this result agrees with many studies ${ }^{18,23}$ that they found the same results which might be due to variation in growth rate, hormonal factor.

\section{Conclusion}

This study indicates that there was a significant difference between the actual birth weight and sonographic estimation of fetal weight using both formulas, so further modification for these formulas or finding a new way for the accurate assessment of birth weight still is in need. Estimation of fetal weight by Hadlock's formula showed a better correlation with actual birth weight than Shepard's formula. The results indicate greater correlation when the time of estimation of fetal weight was less than seven days of delivery time.

\section{Competing interests}

The authors declare that they have no competing interests.

\section{References}

1. Bhandary AA, Pinto PJ, Shetty AP. Comparative study of various methods of fetal weight estimation at term pregnancy. Obstret Gynecol 2004; 54(4):336-9.

2. Ugowu EO, Udealor PC, Dim CC. Accuracy of clinical and ultrasound estimation of fetal weight in predicting actual birth weight in Enugu, Nigeria J Clin Pract 2014; 17(3):270-5.

3. Chauhan SP, Magann EF. Screening for fetal growth restriction. J Clin Obstet Gynaecol 2006; 49:284-94. 
4. Coutinho PR, Cecatti JG, Surita FG, Costa ML, Morais SS. Perinatal outcomesassociated with low birth weight in a historical cohort. BMC Reproduc Health J 2011; 8:18.

5. Fuchs F, Bouyer J, Rozenberg P, Senat MV. Adverse maternal outcomes associated with fetal macrosomia: What are the risk factors beyond birth weight? BMC Pregnancy Childbirth 2013; 13:90.

6. Shittu AS, Kuti O, Orji EO, Makinde NO, Ogunniyi SO, Ayoola OO, et al.Clinical versus sonographic estimation of fetal weight in southwest Nigeria. Nigeria J Health 2007; 25:14-23.

7. Carranza-Lira S, Haro Gonzalez LM, Biruete Correa B. Comparisonbetween clinical and ultrasonographic measurements to estimate fetalweight during labor: A new clinical calculation formula. Br J Obstet Gynecol 2007; 75:582-7.

8. Alnakash $\mathrm{AH}$, Mandan DR. Fetal body weight: How far the clinical and sonographic estimations can coincide and their correlation with the actual birth weight. Iraq J Comm Med 2013; 2:180-3.

9. Pinette MG, Pan Y, Pinette SG, Blackstone J, Garrett John, Cartin A. Estimation of fetal weight: Mean value from Multiple formulas. J Ultrasound Med 1999; 18:813-7.

10. Patrick FW, Chien MD, Philip O, Khalid SK. Validity of ultrasound estimation of fetal weight. Br J Obstet Gynaecol 2000; 95(6,1):856-60.

11. Andrew P, Mackenzie MD, Courtney DS, Edmund FF. Prenatal sonographic assessment of fetal weight. Wolters Kluwer Health; 2015. (Accessed June 2,2016), available from (https://www.uptodate.com/contents/prenatalsonographic-assessment-of-fetal-weight).

12. Bajracharya J, Shrestha N S, Karki C . Accuracy of prediction of birth weight by fetal Ultrasound. Nepal Med Coll J 2012; 38(2):74-5.

13. Alaf S K, Sedik G. Validity of for estimation of fetal weight in term singleton pregnancies. Zanco J Med Sci 2010; 14(3):26-9.

14. Nahum GG, Pham KQ, Mchugh JP. Ultrasonic prediction of term birth weight in Hispanic women. Accuracy in an outpatient clinic. J ReproMed 2003; 48(1):13-22.

15. Edmonds K. Dewhurst's Textbook of Obstetrics and Gynaecology. $8^{\text {th }}$ ed. UK: A John Wiley and Sons, Ltd, Publication; 2012. P. 269-70.

16. Okpere EE, Obesity in pregnancy. Clinical Obstetrics. BeninCity: Uniben Press; 2004. P.121.

17. Ezeanochie MC, Ande AB, Olagbuji BN. Maternal Obesity in Early Pregnancy and Subsequent Pregnancy Outcome in a Nigerian Population. Afr J Reprod Health 2011; 15(4):55.

18. World Health Organization: Child growth standards and the identification of severe acute malnutrition in infants and children; 2009.(Accessed June 8,2016), available from; (http://www.factsforlife.org/pdf/stmt_child growth sam final.pdf).
19. Coutinho PR, Cecatti JG, Surita FG, Souza JP, Morais SS. Factors associated with low birth weight in ahistorical series of deliveries in Capinus. Br Med J 2009; 55(6):692-9.

20. Richards M, Hardy R, Kuh D. Wadsworth M. Birth weight and cognitive function in the British 1946 birth cohort longitudinal population-based study. Br med J 2001; 322(7280):199-203.

21. Njoku C, Emechebe C, Odusolu P, Abeshi S. Determination of accuracy of fetal weight using ultrasound and clinical fetal weight estimation in Calabar south Nigeria. Int SchRes Notices 2014; 4(11):1155-61.

22. Colman A, Maharaj D, Hutton J, Toohy J. Reliability of ultrasound estimation of fetal weight in term singleton pregnancies. N Z Med J 2006; 119(1241):124-8.

23. Voldner N, Frey FK, Godang K, Bollerslev J, Henriksen T. Determinants of birth weight in boys and girls. Hum Ontogenet J 2009; 3(1)7-12. 